\title{
Educational Text and Activity in the Learning Process
}

\author{
Eugene Pavlovich Alexandrov ${ }^{1}$, Marina Viktorovna Vorontsova ${ }^{1}$, Vladimir Evgenyevich Makarov ${ }^{2}$, \\ Yulia Stepanovna Mozdakova² and Yanina Vasilievna Shimanovsky² \\ ${ }^{1}$ Chair of Social and Economic Studies, Russian State Social University, Taganrog - 374923, Russian Federation \\ ${ }^{2}$ Chair of Social Technologies, Russian State Social University, Moscow - 129226, Russian Federation; \\ monblan.pro@yandex.ru
}

\begin{abstract}
The concepts "text" and "text activity" are gradually expanding the area of their application. After the successful practice of their usage in hermeneutics and linguistics, they are decisively invading pedagogical science. Here, the text is understood both as speech fixed on the paper and any other forms of messages addressed to Others or the writer himself as the Other. The result of interacting with texts is not only broadcasting, but also mastering and increasing the social, professional and personal experience of an individual, social groups and the society as a whole. The authors regard the learning process as a specific kind of text activity of its subjects (i.e. both the teacher and the student). At the same time, the authors point out that in the overall structure of the text activity the central place is taken by the processes of counter text generation. The authors state that several types of texts are used in the learning process, among which not only texts, originally created for educational purposes, but also texts somehow adapted for this. The texts produced by the students are particularly important for the educational process. The paper proposes a definition of the concept "educational text", as well as the characteristics of taxa of educational texts.
\end{abstract}

Keywords: Educational Text, Functions of Educational Texts, Taxa of Educational Texts, Text, Text Activity

\section{Introduction}

The ability of socio-cultural experience to be recorded in various texts ensures the reproduction of the society in new generations. Y. M. Lotman ${ }^{1}$ rightly said that culture is created, developed and exists in texts which are understood not only as speech written, recorded on paper or other medium, but as any connected, coherent and relatively complete sequence of semantic units that in their totality form a message addressed to the Other (or to yourself as the other).

Any communicative interaction in the field of culture can be regarded as text activity which is founded on the processes of understanding (interpretation) and generation of texts. Scope and complexity of the problematics of the text and text activity explain the interest in these issues, demonstrated by the scientists working in the field of hermeneutics (F. Schleiermacher,
W. Dilthey, H. Gadamer, M.M. Bakhtin ${ }^{13}$, etc.), linguistics (P. Hartmann, G.P. Shchedrovitskii, G.V. Kolshansky, I.R. Galperin, Y.M. Lotman ${ }^{1}$ and others), psychology (L.S. Vygotsky $^{14}$, V.V. Davydov, A.N. Leontiev, S.L. Rubinstein, D.B Elkonin).

However, considering the text from the pedagogical point of view leads to an incomplete understanding of the problem, which partly explains the contradiction: though the term "educational text" is often found on the pages of modern scientific, educational and methodical literature, none of the modern fundamental reference books provides its definition. It can be stated that regarding the phenomenon and types of educational texts the educational community is dealing with an example of terminology that is widely used in analytical practice, but whose content remains vague. Further in the article we will clarify our position on the educational text, the taxa of educational text and text activity in the learning process.

\footnotetext{
* Author for correspondence
} 


\section{Developing Definitions of the Concept "Educational Text"}

A review of literature on education lets us conclude that the vast majority of authors define the educational text as a source of information originally created for educational purposes which determines the content and processes of the students' cognitive activity. In fact, textbooks, manuals, guides, tutorials, etc. may be without any doubt called educational texts. However, a curriculum, an educational standard, the Law "On Education", despite clearly stated educational goals, cannot be definitely qualified as educational texts.

On the other hand, there are numerous texts used in the learning process, the creators of which did not bear in mind instructional goals. However, with proper methodological support these texts may be really sometimes incredibly - useful in the instruction. Thus, we can conclude that educational goals set by the authors of the text cannot be regarded as the only and sufficient criterion for the text's effective "functioning" as an educational text.

Understanding the educational text solely as the source of information does not correspond with the modern understanding of the learning process as the text activity of a dialogical nature, during which interacting subjects not only fix in memory, perceive, understand, interpret, comprehend, rethink, reproduce, comment, systematize, analyze and compile (etc.), but actually generate (!) new texts. In fact, the intellectual and spiritual potential of developing the personality is achieved through increasing quality level of text generation, since the personality is simultaneously developing itself when creating texts.

In textbooks and manuals the principle of explanation is used for the organization of the learning content, that is, they reveal the essence of phenomena, process patterns, links and relations between the phenomena. Instruction material in them is strictly measured out and structured; it is consistent, systematic, logically organized and, if necessary, is provided with pictures, charts, models and diagrams. As a rule, such methodically processed information sources undergo professional expertise. While being prepared for publication, they are reviewed by leading experts in the particular field of knowledge. However, they often miss the subjectivity of the addresser and the addressee; in most cases, they are intentional neutral, focusing on clear, unambiguous information that does not require any additional interpretation. At the same time, we fully agree with the idea of T.Z. Adamyants ${ }^{10}$ and T.M. Dridze ${ }^{11}$ that there may be no non-intentional communication. In education we can often observe a situation when demonstrative ignorance of intentional positions of the subjects of pedagogical interaction results in communication barriers, communication errors and failures. "Live" teacher "breathes life", intentionally enriches the information with personal meanings which can "resonate" with the semantic systems of the students. On the other hand, strong imposing of the intentional stance may be a destructive factor in the pedagogical interaction.

To ensure the correct perception of the information, say nothing of the intentional position of the author, by the receiving party, the "semantic focus" (the term by T.M. Dridze $^{12}$ ) must emerge, that is the adequate interpretation of the system of signs used in the text by all communicating parties. Of course, the texts that are created with deliberate educational purposes, as a rule, have not only adapted content and structure, but also accurately consider socio-demographic, socio-cultural, psychological and pedagogical specific features of students. Such focused targeting of the text inevitably leads to the situation when different groups react differently to it: For example, trigonometric tasks, being proper educational texts for high school students, are no texts at all and definitely not educational texts, for elementary school students.

The texts, initially created for non-educational purposes, but given the status of instructional materials since they are supplemented with proper methodical support (comments, explanations, refinements, etc.), are widely used in the instruction. For example, the text of a legal state law can become an educational text for law students if the whole course of the previous training and methodological support provide favorable educational environment for their cognitive activity and the purpose of which understands the norms of law, specific aspects of its interpretation and application in certain situations.

In some cases it is setting educational goals, tasks created for students which turn seemingly meaningless sequence of information units (numbers, words, signs, etc.) into the educational text. For example, during language lessons students do grammar or word-building exercises on the material of randomly selected fragments of literary works. Regarding linguistics, this "set" can hardly be described as a holistic text as it has no common literary context. But definitely this "set" is an educational text since its structural elements are selected on the basis of the same educational goals determined by the authors in the accompanying task. 
To understand the phenomenon investigated in this article, we should also take into account the fact that various parties (subjects) create educational texts in the learning process. The subjects of instruction not only perceive and memorize, but also, - and it is more important, - understand, interpret, comprehend, rethink, analyze (establish connections and relations), systematize, comment, compile, reproduce etc. the initial (author's) text, while actually generating (!) the secondary ("counter", their own) texts. There may be no effective exchange of information, achievements of intellectual and empirical experience, values and ideals, norms of behavior and behavioral reactions outside the counter generation of the texts, involving comprehension and interpretation.

That's why considering only side - the teacher's one - will inevitably lead to inaccurate perception of the pedagogical nature of the educational text. In the course of instruction a large number of educational texts are generated by learners themselves or learners together with teachers (when working individually, with a partner, in groups and as a result of a group-to-group interaction). At the same time text-generating activity, as we have noted above, enables learners to develop their personality, broaden their intellectual and spiritual horizons. Educational texts created by the students act as indicators of the development level and effectiveness of the learning process. Self-assessment and students' evaluation of these "increments" provide "feedback", control of the process, during which the achievements are compared with the established norms, qualification requirements and characteristics, accepted values. This forms the basis for developing scenarios for further personal and professional growth.

\section{Literary Text as an Educational Text: Understanding and Interpretation}

Modern educational practices widely use a variety of literary texts (including media texts) aimed at the socialization of an individual, the development of harmonious relationship between the individual and the environment, the enhancement of creative abilities and skills. The literary texts, as a rule, are not built on the basis of the explanatory principle, but are directly designed for "counter" content-generating activity of their addressee.
A characteristic feature of the literary texts perception is that students not only understand them (or, rather, try to understand), but they inevitably construe, interpret, in other words, recreate their cultural contexts "from the perspective of their own personality"s,9.

The terms "understanding" and "interpretation" belong to the categorical framework of hermeneutics. They are quite often used as synonyms, but still somewhat differ in meaning. Philosophical hermeneutics (F. Schleiermacher, Dilthey, G. Gadamer, et al.), defines "understanding" as a form of mastering of the reality by means of consciousness, the purpose of which is revealing and reproduction of the semantic content of the text. Through understanding the new information is incorporated into the existing system of reality perception that an individual has. Understanding is defined not only by the influence of social, cultural and historic contexts but also by a unity, an interconnection with selfunderstanding through a comparison of the semantic contexts of what is being learnt and the one learning. Here we should describe the stages of understanding: Firstly, it is initial understanding (resulting from synthetic "grasping" of the whole image), next comes analytical understanding that is trying to confirm or deny the meaning of the whole contrasting it with the meaning of its components; and, finally, understanding of the whole picture ("assembling" the results of analytical activity in the new holistic manner) that is confirmed by the meaning of its parts, while the meaning of the parts is verified by the meaning of the whole. It is the third stage when the whole life experience of an individual is engaged and this enables the operations of comparison, contrasting, categorization, typology etc. The operations of abstraction (excluding nonessential, specific, random features) and generalization (finding common properties and features) play an important role here.

Interpretation in hermeneutics is understood as an act of attaching meaning to this or that element of knowledge and reality. Meaning, contained in the text, is reinterpreted, the content of original semantic forms is "melted" in accord with the perspective, different from the author's position - the interpreter's perspective. In fact, here we are talking about creation of new meaning, the meaning "generated by oneself" and the meaning "for oneself". This provides an opportunity to expand the time frame of the work of art; literary texts, created in the previous eras, can remain relevant to the human, living in the modern context, since 
in them he searches for and discovers ideas that are in tune with his existence, but which, perhaps, were not implied by the author of the text.

Hermeneutic methodology assumes that there may be more than one correct interpretation of the text. The meaning is stereoscopic, variable; it is based on the previous experience of the individual, on his intentions generated in the course of other acts of socio-cultural communication, which makes it possible to bind together the "integral fabric of knowledge" of the past, present and future and to find familiar elements in the unknown material, to fill in the gaps in the meaning.

\section{Definition of the Term "Educational Text"}

This allows us to conclude that the educational text should be defined as the text used by the subjects of the educational process for their text activity in forms of textperception and text-generation, which enables to meet certain didactic, developmental and educational goals. A text becomes an educational one when it is designed, created, transformed, adapted, analyzed, commented, interpreted (comprehended and rethought)by the subjects of the learning process for the development of the individual's intellectual and spiritual potential.

Main functions of the educational text are the following:

- Transfer of educational content regarding the socio-demographic and individual psychological characteristics of students;

- Formation, development and training of cognitive and creative abilities and skills of students;

- Facilitating students' cognitive activity;

- Socio-cultural development of students;

- Enhancing learners' analytical and reflective-analytical competence;

- Enhancing students' motivation;

- Control (self-control) of the outcomes of educational activities and the quality of the learning process.

\section{Taxa of the Educational Text}

Analyzing educational texts from pedagogical position, we can define some basic taxa of educational texts:

1. Texts created by the party, directly organizing the educational process, for didactic and diagnostic purposes:
- Textbooks, Teaching Aids, Guidelines and Resources, Self-Study Books, Lectures, Guidelines for Labs, Notes, Etc.

As a rule, they are didactic, their content and structure have a clear target, that is, they are determined, on the one hand, by characteristics of a particular science, school subject or a type of the socio-cultural practices (including the environment in which this practice takes place) and on the other hand - by the specific features of teachers and students. As a rule, they are designed according to the explanatory principle, that is, they reveal the essence, the basic laws of the studied processes and objects and, therefore, are characterized by clear, unambiguous meaning, with no need for further interpretation;

- Texts, made from other texts, the ones of non-academic nature and used in the instruction in such ways which their authors, even indirectly, did not imply. For example, a new text is created from disconnected "text fragments", which pursues the goals that were not assumed in the initial material, but are of didactic nature;

- Texts with Diagnostic Purposes

For example, a variety of didactic tests, assignments, questions. Here we should bear in mind that many test materials used in the instruction actually have no diagnostic value, since they have not passed statistical tests for validity, have no scientifically based weighing factors, do not specify the area of their application, which severely limits their use (or makes it impossible and even inappropriate). In addition, it should be stated that diagnostic materials can carry information not only about the personality (for the analysis of the current state and predicting its development) or its level of training, but also they can provide details on the learning process, its compliance with capabilities and intentions of students, which, in turn, facilitates the use of individual and differentiated approaches.

1. Texts created by students, including those emerging in the course of interpersonal, person-group and group-to-group interactions. After a variety of "manipulations" with the text, students either acquire or develop knowledge and skills, subjectively new for them and form the semantic system. At the same time, these texts can be a sort of "indicators" of qualitative changes in the outcomes of instruction. Here we can consider several subgroups of texts:

- Compilations - A new text is created when selecting fragments of texts by other authors according to a given topic, which enables comparison (and in some cas- 
es - contrasting) several points of view, controversies, dialogues. Reports and summaries may be considered examples of this type of educational texts;

- Training educational texts should provide an opportunity for skills development, practice in the application of the material learnt, establishing working links between theoretical information and learners' reflective and analytic experience. As a rule, they are designed according to a specific, predetermined algorithm. Tasks on solving problems and exercises in a math or native language class are examples of this type of educational texts;

- Creative educational texts are intended to enhance the creative potential of students and include the following types of their works (certainly, in education most of them are texts created under the impression of some work of art, when thinking and rethinking, through a significant revision of other sources): for example, essays, compositions, research projects, etc.;

- Contextual educational texts are aimed at developing skills of interpretation of the texts written by other authors. They are the result of the meaning-generating activity and engage the life, educational and socio-cultural experience of the students, their reflexive and analytical skills: for example, plans to texts, abstracts, comparative analysis, etc.;

- Diagnostic educational texts are used for external control and self-control. Students create various texts, the quality of which is an indicator of the success of the learning process. As a rule, such texts are designed to reveal the most significant details of the material studied, to identify hierarchies, interdependences, relations between elements. Strictly speaking, any of the above subtypes of educational texts can perform diagnostic functions, but here we primarily speak of texts indicating how deep and well the material was learned;

- Qualification texts are designed to confirm that the author possesses a certain level of professional qualifications. Such texts typically involve certain procedures for external expertise and review as well as public defense of the theoretical positions and practical recommendations formulated in the text. As a rule, the qualification texts are clearly structured in accordance with the established requirements for scientific and qualification papers. The style of the text should comply with many requirements: limiting the usage of "literary arabesques", the author should be laconic and at the same time provide clear arguments, evidences in the wordings of the defended positions.
1. Texts, created by teachers and students in collaboration. In this case it is important to limit the participation of the teaching party to avoid suppressing the learners' activity with an excessive effort. Teachers' guidance should be primarily aimed at ensuring the common vision of work planned, uniform logic in understanding and presentation of the material. Moreover, this draft of the future text should be not solely the teacher's achievement, but most importantly - the one of a student. Only in this case the student turns from a mere executor of the will of others into a creatively charged subject of instruction.

1. Texts with no educational component in its original state, but acquiring the status of educational ones for certain didactic purposes. For example, the texts:

- Used in their original form or subjected to a partial didactic adaptation (such as splitting them into fragments, reflecting temporary and contextual stages of acquisition); this improves the efficiency of cognitive activity and phase control of their quality;

- Used in their original form, but accompanied with texts that motivate, accentuate, analyze and comment and are created by other authors (considering the methodical aspect). For example, some authentic contexts of Pushkin's novel in verse can no longer be correctly interpreted by modern readers and need further clarification. The well-known opening lines:

My uncle - high ideals inspire him;

but when past joking he fell sick,

he really forced one to admire him -

and never played a shrewder trick.. (...)

(tr. by Charles H. Johnston).

should be accompanied by the comment that the expression "forced one to admire him" during the time of Alexander Pushkin had a semantic meaning "to die", which fundamentally changes the perception of the text's intention: The character of the novel is "flying through the dust on a mail coach" in the hope of coming into inheritance, while his uncle has already died and does not require nursing, so burdensome for a young person.

Another striking example is a well-known extract by A.S. Griboyedov -

He was in service in Catherine's days. And

Everybody felt important then,

Your bow and scrape they would disdain.

A courtier was even better off,

He'd eat and drink what others didn't dream of. -

(tr. by A.S.Vagapov) 
cannot be properly understood either, unless an important explanation is provided: "A courtier in case" (the word-for-word translation of the phrase used by the author) denotes not just a important nobleman, but a favorite of Catherine 2, who received a special social status and social roles associated with it.

We should note that in some cases these accompanying texts can acquire their own educational value because one way or another they reflect the intentionality and the course of the authors' analytical work and they themselves can become a kind of "exercise" for observation and analysis (e.g., literary criticism);

- Texts large in volume or considerable factual content, with polyphonic intentions - not all of them can and should be comprehended and mastered by students during a particular time period; these works are transformed into educational texts by combining the authentic author's fragments and fragments written by others (for the learning process) by the authors, the purpose of which, for example, is to describe the progress or the meaning of the events taking place in the omissions. One more option of text adaptation for educational purposes is when omissions are not followed by the comments.

1. Texts originally created for extracurricular purposes (for example, so-called literary texts, including media texts), but that are used to solve didactic and educational tasks by means of:

- Their comparative juxtaposition in the educational process. Here it is possible to simultaneously use texts themselves and specific "reminders" integrated in the personal experience of students. In this case educational activities are directed at the search for meaning, generated not only by the texts themselves but more by their juxtaposition, which "strikes sparks" of the new meanings, not directly present in the source text. For example, two poetic works on the same theme are selected and a comparative analysis of their characteristics is conducted (language, rhythm, images, style - both individual and characteristic of the era, etc.);

- Interpretation and understanding, "elaboration of meaning" in the minds of the audience, i.e. providing a counter meaning-generating activity (and, hence, creative by nature) when the "core meaning" is not actually present in the text and the creators of the text only prepare students to give an independent response to the questions of being raised in the text. This is possible only if students can recognize at least some familiar elements in the unknown as well as rely on their own socio-cultural and psychological experi- ence. Here the educational process is aimed at understanding the dramatic idea or concept; therefore, its structure is significantly influenced by psychological characteristics of artistic perception.

In some cases, for instructional purposes it is possible to use texts that do not actually belong to the socio-cultural sphere in the framework of which interpretations should be made: For example, fiction and media texts are used in the course of psychology students training for the analysis of subtle, hidden aspects of the psyche functioning.

\section{Conclusion}

At the end of our analysis we would like to emphasize that approaching the problem of the educational text from the teacher's perspective sheds new light on it, while this gap in didactic theory inevitably limits the range of methodical techniques used by a teacher. Perhaps the most important conclusion of our discussion is that 1 . every educational process is at its root a text activity; 2 . the development of intellectual and spiritual aspects of the students' personality should not be limited to text activity in the forms of understanding and interpretation, but it should also include generation of educational texts; 3. in the course of training its subjects use and produce a "set" of educational texts with different functions, 4 . with no intention to downplay the role of understanding of the text, we would like to emphasize the importance of interpretation, due to which the information drawn from the text by means of creative rethinking can become the acquisition of an individual, the basis for the subsequent search for effective solutions in unusual life and professional situations.

\section{References}

1. Lotman YM. Izbrannye stati: v 3 t. T.1. Izbrannye stati po semiotike i tipologii kultury [Selected articles in 3 vol. Vol.1. Selected articles on semiotics and typology of culture]. - Tallinn: Alexandria. 1992; 30-8. [in Russian].

2. Aleksandrov EP. Uchebnyj tekst: opyt definicii i tipologicheskogo analiza [Educational Texts: Definition and typological analysis]. Current Issues of Communication and Culture-7. International collection of scientific papers. -Pyatigorsk, Moscow: Publishing House of the Pyatigorsk state linguistic University. 2008. p. 202-7. [in Russian].

3. Valgina NS. Teoriya texta: uchebnoe posobie [Text theory: Textbook]. - Moscow, Logos. 14.10.2015. 2003. Available from: http://evartist.narod.ru/text14/01.htm [in Russian]. 
4. Vinogradov PN., Yarkin PA. Psihojekologicheskij analiz usvoenija soderzhanija estestvennonauchnyh tekstov [Psycho-ecological analysis of mastering the content of science texts]. Usage of Texts in Modern Higher School, Ed. prof. E. Alexandrov. - Taganrog: Publishing house of the Taganrog state pedagogical University. 2007. p. 9-28. [in Russian].

5. Adamyants TZ. V poiskah emocionalnogo i smyslovogo konteksta (po materialam innovacionnyh seminarov, posvjashhennyh otrabotke kommunikativnyh navykov) [Searching for emotional and semantic context (based on innovative workshops devoted to developing communication skills)]. World of Psychology. 2002; 4(32):178-86. [in Russian].

6. Dridze TM. Socialnaja kommunikacija kak tekstovaja dejatelnost v semisociopsihologii [Social Communication as
Text Activity in Semisociopsychology]. Social Studies Todday. 1996; 3:145-52. [in Russian].

7. Dridze TM. Ot germenevtiki k semiosociopsihologii: ot "tvorcheskogo" tolkovanija teksta k ponimaniju kommunikativnoj intencii avtora [From Hermeneutics to Semiosociopsychology: from "Creative" Interpretation of the Text to Understanding the Communicative Intention of the Author]. 2000. 14.10.2015. Available from http://www.auditopium.ru \books $\backslash 2152 \backslash$ g19.pdf [in Russian].

8. Bakhtin MM. Voprosy literatury i estetiki [Questions of literature and aesthetics]. - Moscow: Khudozhestnennaya literature; 1975. [in Russian].

9. Vygotsky LS. Psikhologija iskusstva [Psychology of Art]. Moscow: Iskusstvo; 1965. [in Russian]. 